\title{
A natureza da ciência por meio do estudo de episódios históricos: o caso da popularização da óptica newtoniana
}

(The nature of science through historical episodes: the case of the popularization of Newtonian optics)

\author{
Cibelle Celestino Silva ${ }^{1}$ e Breno Arsioli Moura ${ }^{2}$ \\ Departamento de Física e Informática, Instituto de Física de São Carlos, \\ Universidade de São Paulo, São Carlos, SP, Brasil \\ Recebido em 30/8/2007; Aceito em 18/12/2007
}

\begin{abstract}
Apesar das dificuldades em abordar a natureza da ciência em sala de aula, há um entendimento geral da necessidade de incorporar nos currículos noções sobre como ocorre a construção do conhecimento científico. Conhecer a história do desenvolvimento e do processo de aceitação de teorias científicas pode ajudar os professores a incluir discussões sobre a natureza da ciência no ensino de ciências. Este trabalho apresenta uma análise da aceitação e propagação das teorias sobre luz e cores de Newton ao longo do século XVIII. Apontaremos para alguns aspectos da natureza da ciência que podem ser evidenciados pelo estudo desse episódio histórico.

Palavras-chave: natureza da ciência, história da física, Newton, óptica, século XVIII.
\end{abstract}

Despite the difficulty of precisely describing the nature of science, there is a widespread agreement concerning the necessity of incorporating into curricula some notions about how the scientific activity works. Studying the history of conceptual development and the process of acceptance of scientific ideas by the scientific community may help teachers to incorporate notions of nature of science in their classes. The present paper analyses the development and acceptance process of Newtonian optics during the eighteenth century in Europe, and emphasizes some aspects of nature of science that can be learned by the study of this historical episode.

Keywords: nature of the science, history of physics, Newton, optics, $18^{\text {th }}$ century.

\section{Introdução}

Nos últimos anos, pesquisas com estudantes e professores de nível médio têm mostrado que, em geral, eles apresentam interpretações simplistas sobre a natureza da ciência, como uma forte visão indutivista, desconsiderando o papel da criatividade e da imaginação na produção do conhecimento científico e exibindo uma falta de compreensão das diferenças entre fato e evidência, observação e experimentação, entre outras lacunas [1-3].

Há um crescente consenso entre pesquisadores e educadores de que a aprendizagem $d a$ ciência deve ser acompanhada por uma aprendizagem sobre a ciência [4-6]. A aprendizagem sobre a ciência deveria incluir elementos tais como sua relação com a cultura e a sociedade, o caráter mutável das idéias científicas, a humanização dos cientistas, entre outros. Esses aspectos fazem parte do que os filósofos e epistemólogos chamam de natureza da ciência (NDC).

A NDC é um conjunto de conhecimentos sobre a

\footnotetext{
${ }^{1}$ E-mail: cibelle@ifsc.usp.br. ${ }^{2}$ E-mail: brenoam@if.usp.br.
}

ciência que trata de seus métodos, objetivos, limitações, influência, etc, sendo sua inclusão no ensino de ciências uma das metas atuais da educação [7, p. 13]. Nesse sentido, o estudo de episódios particulares da história da ciência pode fornecer subsídios para a discussão de aspectos da NDC em sala de aula, uma vez que oferece uma visão mais profunda e detalhada do processo de construção do conhecimento científico.

A aceitação e propagação na Grã-Bretanha do século XVIII das teorias sobre luz e cores presentes no Óptica de Isaac Newton (1643-1727) é um episódio da história da ciência que pode contribuir para a discussão de aspectos da natureza da ciência em sala de aula. Geralmente, há uma visão inadequada de que as teorias ópticas newtonianas - que eram baseadas implicitamente numa concepção corpuscular para a luz permaneceram superiores em relação a outras teorias do período (por exemplo, a vibracional), sendo rejeitadas somente nas primeiras décadas do século XIX. Este tipo de idéia ingênua não sobrevive a um estudo histórico mais aprofundado. Uma análise detalhada 
desse processo mostra que a óptica corpuscular newtoniana passou por, pelo menos, dois períodos distintos no século XVIII. Nas primeiras décadas, as teorias de Newton não foram seguidas completamente em suas formas originais, mas reformuladas e incorporadas em um modelo dinâmico para a óptica. Este modelo era baseado em conceitos que não foram discutidos abertamente por Newton, como a materialidade da luz e sua interação com os outros corpos por forças agindo a uma determinada distância. A situação só mudou a partir da metade do século XVIII, quando outras teorias para a luz começaram a ser aperfeiçoadas e problemas nesse modelo dinâmico tornaram-se evidentes e sem solução satisfatória.

O presente artigo apresenta um estudo histórico desse episódio, evidenciando que a construção do conhecimento científico não é simples e linear como geralmente se acredita, possibilitando a compreensão de diversas características relevantes da natureza da ciência.

\section{O Óptica}

O livro Óptica [8], publicado pela primeira vez em 1704, contém uma ampla discussão de tópicos da óptica, tais como associação entre cor e refrangibilidade; teoria das cores, natureza da luz, explicação para os fenômenos atualmente conhecidos como polarização, interferência e difração. Newton também discutiu questões relativas à mecânica, tais como a existência de um éter universal e ação de forças a distância.

O Óptica é dividido em três livros, cada um deles explorando diferentes temas da óptica. O Livro I contém discussões principalmente sobre a composição da luz branca, em que Newton expõe seus famosos experimentos com prismas. ${ }^{2}$ O Livro II tratou dos fenômenos dos anéis de cores em filmes finos, conhecidos como "anéis de Newton". Atualmente, explicamos esse fenômeno mediante o conceito de interferência entre ondas luminosas, porém, Newton não aceitava qualquer tipo de concepção ondulatória para a luz, elaborando o conceito de estados de fácil transmissão e estados de fácil reflexão ${ }^{3}$ para explicá-lo. Segundo ele, os raios de luz, dependendo do estado em que estivessem e da espessura do filme seriam transmitidos ou refletidos, ocasionando os vários anéis coloridos.

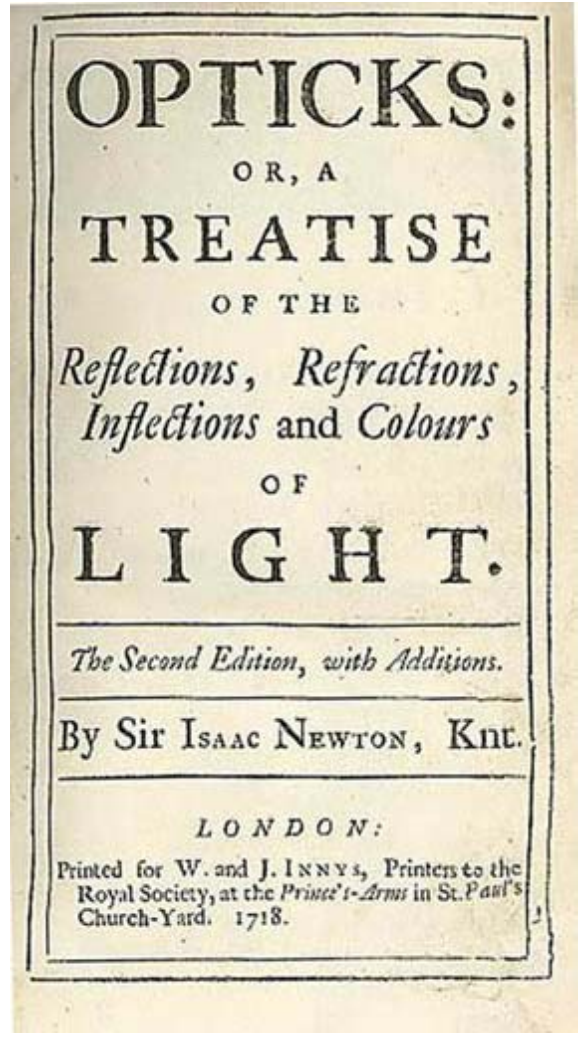

Figura 1 - Capa da segunda edição em inglês do Óptica.

O conceito de estados da luz fazia parte de um projeto maior de Newton. Sua intenção era desenvolver um modelo explicativo único para tratar tanto o fenômeno dos "anéis de Newton" quanto outros, como a refração e a reflexão [9]. Newton considerava os estados como sendo propriedades originais dos raios de luz, com sua existência comprovada pelos experimentos com os anéis de cores em filmes finos. Segundo ele, isso por si só dispensaria um tratamento mais detalhado de suas origens e causas, não sendo este uma das prioridades do Óptica $[8$, p. 212]

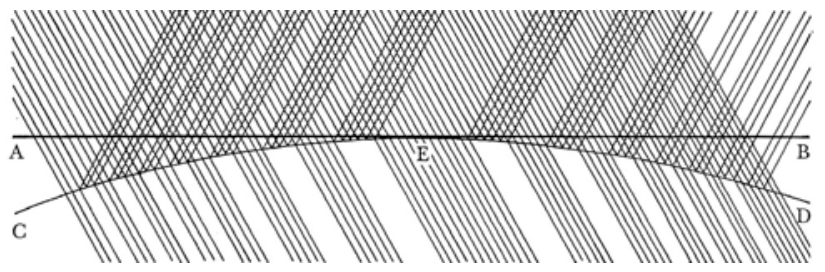

Figura 2 - Esquema de Newton no Óptica para ilustrar o aparecimento dos anéis de cores numa película fina de ar entre as superfícies de duas lentes.

\footnotetext{
${ }^{2}$ Para um estudo mais aprofundado sobre o Livro I veja a Ref. [10].

${ }^{3} \mathrm{O}$ termo em inglês originalmente utilizado por Newton para designar esta propriedade da luz foi fits of easy reflection and transmition. Na época, segundo o Oxford English Dictionary, o termo "fits" era utilizado freqüentemente na área médica para designar o ataque repentino, mas transitório, de algum tipo de doença. Newton foi o primeiro a utilizá-lo em óptica. Esse termo foi traduzido para o português como "caminhos", "acessos", entre outras palavras. No entanto, preferimos utilizar o termo "estados", como adotado na edição em português do Óptica. Pelo estudo do Óptica e dos trabalhos anteriores de Newton sobre o assunto, vemos que a palavra "estados" é a que melhor representa o significado do termo fits utilizado por Newton. Isso aparece claramente na proposição 12 do Livro II, na qual ele afirmou que o fato de um raio ser transmitido ou refletido é conseqüência de que Every Ray of Light in its passage through any refracting Surface is put into a certain transient Constitution or State, which in the progress of the Ray returns at equal Intervals, and dispose the Ray at every return to be easily transmitted through the next refracting Surface, and between the returns to be easily reflected by it. [grifo nosso]
} 
Outro assunto tratado no Livro II foi a interação da luz com a matéria. Newton inferiu sobre várias propriedades microscópicas dos corpos, afirmando que eles seriam constituídos de partes e poros que, ao interagirem com a luz, poderiam ocasionar a opacidade, transparência e cores dos corpos.

O Livro III abordou o fenômeno da inflexão da luz, que conhecemos hoje como difração. Newton descreveu experimentos com fios de cabelos, facas e réguas, discutindo o surgimento de franjas claras, escuras e coloridas, partindo da idéia de que a luz seria atraída de alguma forma pelos corpos. No final, ele apresentou as famosas Questões, contendo especulações sobre diversos assuntos, por exemplo, sobre a dupla refração e sobre alguns fenômenos químicos.

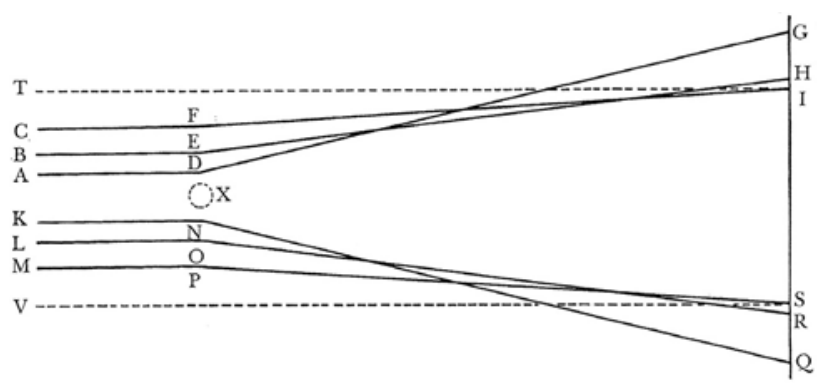

Figura 3 - Newton sobre a inflexão da luz. X seria um fio de cabelo, que faria com que feixes de luz passando perto dele fossem divergidos de sua trajetória devido a ação de forças entre o fio e os corpúsculos de luz.

O impacto do Óptica praticamente se igualou ao provocado pelo primeiro e mais conhecido livro de Newton, os Princípios Matemáticos da Filosofia Natural, ou Principia, publicado em 1687. Enquanto este último foi escrito em latim e trazia uma pesada linguagem matemática, o primeiro foi baseado essencialmente na discussão de experimentos e proposições, sem utilizar muitos conceitos matemáticos [10, p. 2]. Justamente por ser uma obra de fácil acesso e de leitura agradável, Óptica se mantém como uma obra que desperta grande interesse até hoje.

No entanto, é necessário cautela ao falarmos sobre o livro. Freqüentemente, o Óptica é considerado como a exposição final e completa da concepção corpuscular para a luz de Newton, que seria muito semelhante à concepção corpuscular atual, e traria uma semente para a idéia de dualidade onda-partícula. Há algumas interpretações inadequadas e anacrônicas em livros e páginas na internet, afirmando que, com teoria dos estados, Newton procurou unir as concepções ondulatória e corpuscular para a luz ou até mesmo que os estados seriam antecipações de conceitos atuais da mecânica quântica [11-15]. Porém, estudos recentes mostram que as idéias de Newton estavam muito longe de se adequarem a essas afirmações $[9,16]$.

De fato, Newton adotou implicitamente uma concepção corpuscular para a luz em seus trabalhos sobre óptica. No entanto, um modelo dual era algo completamente inconcebível para ele e para os pesquisadores do período. Para explicar a formação dos anéis coloridos em filmes finos no Livro II, Newton adotou vários modelos diferentes. Em um deles, supôs que os corpúsculos de luz excitariam vibrações periódicas no éter luminoso, o que é completamente diferente de supor que a luz tenha um caráter dual.

Exceto em trabalhos com um caráter assumidamente especulativo, ${ }^{4}$ Newton evitou explorar abertamente questões relativas à natureza da luz, freqüentemente utilizando as palavras "raio de luz", um termo geral que não se refere explicitamente à natureza corpuscular da luz. Apesar de ser conhecido como grande defensor da concepção corpuscular da luz, seus trabalhos publicados, principalmente o Óptica, não apresentam uma exposição detalhada do assunto [18].

O Óptica é uma obra que abrange uma grande gama de assuntos, muitos deles novos e ainda não completamente estabelecidos na época. Justamente por isso, é natural que houvesse diferentes idéias em discussão, idéias estas muitas vezes contraditórias entre si. Análises históricas recentes apontam várias dificuldades enfrentadas por Newton para realizar muitos dos experimentos descritos e também elaborar modelos para explicar alguns dos resultados obtidos baseando-se implicitamente na concepção corpuscular da luz $[9,10,11$, $16,18,19]$.

\section{A óptica newtoniana no início do século XVIII}

A teoria de Newton sobre luz e cores presente no Óptica exerceu grande influência sobre os estudos de óptica desenvolvidos no início do século XVIII na Grã-Bretanha e Europa. O Livro I e as Questões do Livro III foram as partes da obra que mais chamaram a atenção dos pesquisadores desse período.

O Livro I, ao apresentar descrições detalhadas de diversos experimentos projetados para demonstrar a heterogeneidade da luz branca, serviu como um grande reforçador do ideal indutivista sobre a construção do conhecimento científico, muito popular na época. Esse livro trouxe uma vasta discussão de experimentos e seus resultados com o objetivo de levar o leitor a crer que as idéias e conceitos nele defendidos haviam sido estabelecidos usando-se apenas argumentos experimentais. Atualmente sabemos que isso é uma impossibilidade, já que os próprios experimentos foram projetados com o objetivo de evidenciarem certas hipóteses estabelecidas antes da realização dos mesmos. Além disso, Newton utilizou argumentos epistemológicos para fundamentar suas idéias, embora implicitamente [19].

As Questões, por outro lado, apresentaram discussões conceituais sobre a materialidade da luz e sua

\footnotetext{
${ }^{4}$ Por exemplo, no artigo "A hipótese da luz", enviado à Sociedade Real de Londres em 1675. Ver Ref. [17].
} 
interação com os outros corpos por forças agindo à distância. Este tipo de argumentação foi importante para que os newtonianos do século XVIII fundamentassem a relação entre a dinâmica de partículas de Newton e suas teorias sobre luz e cores. Para a maioria dos adeptos da concepção corpuscular da luz, a óptica deveria também se inserir no sistema newtoniano de interação entre os corpos presente nos Principia.

Tudo isso motivou um processo de transformação das teorias newtonianas, fazendo com que os seguidores de Newton elaborassem diversas teorias sobre luz e cores, baseadas na materialidade da luz e na sua interação com os corpos por forças atuando a distância, tendo o indutivismo como fundamento epistemológico. A intenção desses cientistas era elaborar uma base coerente e bem fundamentada da concepção corpuscular da luz, utilizando um modelo dinâmico para explicar os diversos fenômenos ópticos conhecidos na época.

Um dos aspectos mais interessantes desse processo foi que muitos autores consideraram aspectos da concepção corpuscular não desenvolvidos a fundo por Newton. Além disso, certos conceitos newtonianos, tais como os estados de fácil transmissão e fácil reflexão da luz, que não puderam ser incorporados no modelo dinâmico para a luz foram completamente ignorados ou tratados superficialmente. Ainda que os estados da luz fossem considerados fundamentais por Newton, eles não foram integrados ao modelo dinâmico para a luz desenvolvido posteriormente por seus seguidores.

Sendo assim, apesar de a obra de Newton ter exercido grande influência nos estudos sobre luz e cores desenvolvidos no início do século XVIII, podemos dizer que o que foi propagado como sendo a óptica newtoniana afastou-se muito dos conceitos e idéias defendidos nos trabalhos publicados por Newton. Isto porque um dos objetivos dos newtonianos do período era construir um corpo de conhecimento sobre os fenômenos ópticos baseados em pressupostos como a materialidade da luz e a sua interação com os corpos por meio de forças; o que seria inviável se conceitos considerados fundamentais para Newton, como os estados da luz, também fossem incorporados na nova óptica. Desta forma, estes conceitos deixaram de ser tratados e discutidos poucas décadas após a publicação do Óptica.

\section{Um modelo dinâmico para a óptica}

Um dos primeiros trabalhos a conter discussões sobre a óptica newtoniana a partir da relação entre dinâmica de partículas e fenômenos ópticos foi o segundo volume do Lexicon Technicum de John Harris (1666-1719), publicado originalmente em 1710, ou seja, cerca de 6 anos após a publicação do Óptica. Nesse dicionário científico, Harris explorou no verbete light a variedade de argumentos a favor da materialidade da luz descritas nas Questões do Óptica. No entanto, a invés de explorar o caráter hipotético das discussões newtonianas, Harris transformou o que era uma questão para Newton em afirmação.

Portanto, os raios de luz são certamente pequenas partículas, realmente emitidas do corpo luminoso e refratadas por alguma atração, pela qual a luz e o corpo sobre o qual ela cai agem mutuamente um no outro, pois tais partículas ou corpúsculos serão transmitidos através de meios uniformes em linhas retas, sem qualquer inflexão, como os raios de luz fazem. [20, verb. light, grifo nosso].

No Óptica, Newton não defendeu abertamente a materialidade da luz e apresentou poucas discussões sobre a ação de forças sobre os raios de luz. As palavras de Harris demonstram, por um lado, a aceitação das idéias de Newton, e por outro, a evidente transformação e modificação de suas teorias. Este tipo de atitude está presente em muitos trabalhos de seguidores das teorias newtonianas do período.

Outra obra a explorar um modelo dinâmico para explicar os fenômenos ópticos foi o Mathematical Elements of Natural Philosophy (1720-1721), do filósofo natural dinamarquês Wilhem Jacob 'sGravesande (1688-1742). Seu livro contribuiu fortemente para o estabelecimento da ciência e filosofia de Newton, sendo muito lido no século XVIII [18, p. 35].

Ao contrário da maioria dos seguidores das teorias newtonianas, 'sGravesande, assim como Newton, não discutiu em detalhes a materialidade da luz, restringindo-se a afirmar que ela seria algum tipo de fogo.

Quando o fogo entra nos seus olhos em linhas retas, pelo movimento que ele propaga às fibras no fundo do olho, ele excita a idéia de luz [...]. [21, p. 14]

Nos trechos seguintes dessa obra, 'sGravesande elaborou o conceito de "espaço de atração", que explicaria a refração e a reflexão total. Segundo ele, entre duas superfícies de meios de densidade diferentes, haveria uma região em que o raio sofreria uma maior atração do corpo mais denso, fazendo com que ele fosse desviado de seu caminho retilíneo e sua trajetória ficasse mais próxima à normal em relação à superfície desse meio.

Para 'sGravesande, o raio, após ser refratado pelo meio mais denso e ultrapassar o limite do "espaço de atração", seria atraído igualmente por todos os lados, seguindo novamente uma trajetória retilínea. 'sGravesande detalhou esse conceito, que representou o aspecto principal de suas discussões sobre luz e cores. 


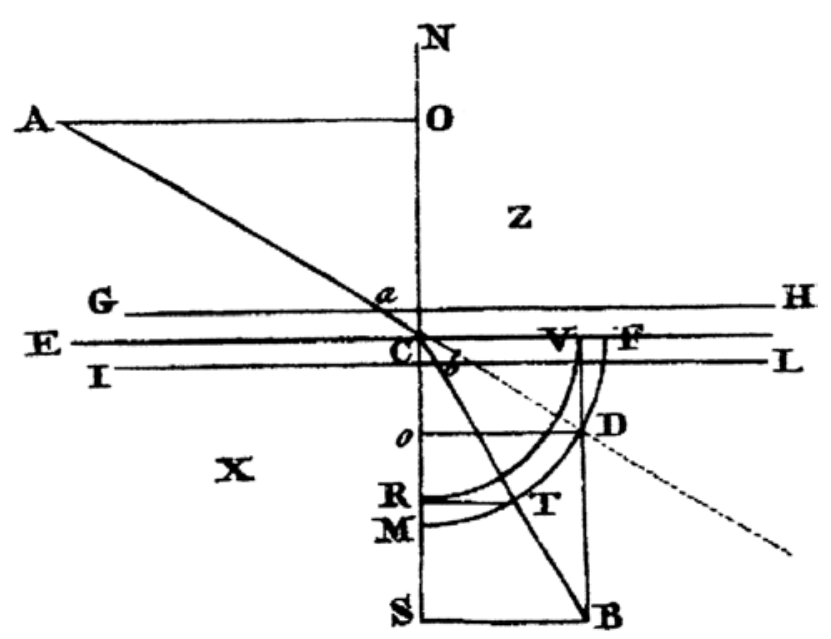

Figura 4 - Ilustração do Mathematical Elements que mostra a refração da luz. X e Z seriam, respectivamente, os meios mais e menos densos. O "espaço de atração" se limitaria entre as linhas GH e IL.

No entanto, o conceito de "espaço de atração" de 'sGravesande encerra alguns problemas básicos. Não é possível, por exemplo, explicar a partir desse conceito a reflexão, pois ele não ofereceu argumentos que mostrem como o raio estaria sujeito a uma eventual repulsão pelo corpo. Além disso, fenômenos como a reflexão e refração parciais também ficaram sem explicação. Outro problema no "espaço de atração" se refere à determinação de seus limites, o que não foi abordado por 'sGravesande.

Assim como outros autores do período, a análise dinâmica de 'sGravesande se resumia principalmente à explicação de fenômenos como a refração e a reflexão total a partir do conceito de força atrativa. Em outras edições do Mathematical Elements, ele procurou explicar a reflexão a partir do conceito de força de repulsão, mas não desenvolveu completamente suas idéias [18].

Robert Smith (1689-1768) em seu A Compleat System of Optics (1738) elaborou um conceito semelhante ao de "sGravesande, o qual denominou "espaço de atividade". Segundo ele, o poder de um corpo se estenderia até dois planos limites, paralelos um ao outro e à superfície do corpo. Quando um raio de luz entra no "espaço de atividade",

[... suas partículas serão aceleradas ou retardadas na mesma direção perpendicular, conforme o poder do meio agir a favor ou contra o curso de seus movimentos; e quando as partículas saem daquele espaço, elas prosseguirão com uma velocidade uniforme. [22, p. 21]

O "espaço de atividade" teria regiões tanto de repulsão, que fariam com que o raio fosse refletido, e regiões de atração, que fariam com que o raio fosse refratado ou refletido totalmente. A intensidade da atração ou repulsão dependeria da densidade refrativa do corpo (ou índice de refração, em linguagem atual).

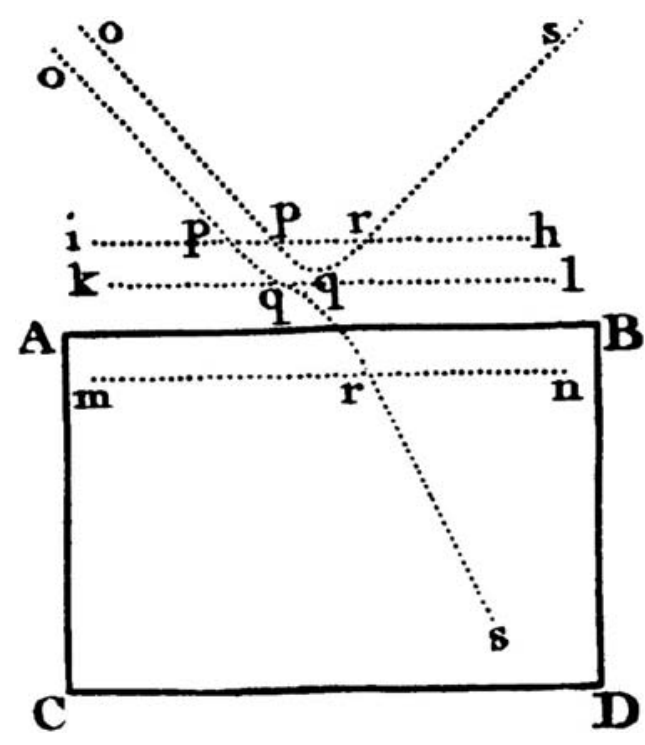

Figura 5 - Smith e seu "espaço de atividade", que estaria entre as linhas $i h$ e $m n$. A região de atração se limitaria entre $k l$ e $m n$ e a região de repulsão entre $k l$ e $i h$.

Como vemos, Smith foi um pouco além de 'sGravesande ao discutir regiões de repulsão que fariam com que o raio fosse refletido pelo corpo mais denso. Contudo, suas explicações apresentam problemas semelhantes ao do "espaço de atração", por exemplo, em relação aos limites do "espaço de atividade" e também o fato de ele ter estabelecido a existência de uma região de repulsão somente no meio mais denso, não esclarecendo se haveria também uma região semelhante no meio menos denso.

O "espaço de atração" de sGravesande e o "espaço de atividade" de Smith são muito semelhantes a conceitos pouco desenvolvidos por Newton em alguns de seus trabalhos sobre óptica. No artigo "Hipótese da luz" de 1675, Newton discutiu as propriedades do éter e sua interação com os raios de luz. Segundo ele, os poros dos corpos seriam preenchidos por éter. Quanto maior a densidade desses corpos, menos poros e, portanto, menos éter. A partir disso, ele afirmou que existiria uma região entre corpos de densidade diferentes, onde atuaria uma pressão do corpo que possuía mais éter - por exemplo, o ar - em direção àquele que possuía menos éter - por exemplo, o vidro. Isso explicaria fenômenos como a refração e a reflexão total da luz [17, p. 41].

No Óptica, Newton não abordou explicações envolvendo o éter, considerando no Livro II que fenômenos como a refração seriam explicados pela ação de uma força agindo a uma determinada distância dos raios de luz. Os limites de atuação dessa força, Newton chamou de "espaço de atividade da superfície refratora" [8, p. 205]. Contudo, assim como os conceitos do "Hipótese", Newton não entrou em detalhes acerca desta idéia.

Os conceitos de "espaço de atração" de "sGravesande e "espaço de atividade" de Smith representam, 
de uma certa maneira, uma evolução com relação às explicações superficiais dos trabalhos anteriores de Newton, pois eles procuraram descrever detalhadamente a ação de forças sobre os raios de luz. Isso evidencia o processo de transformação e aperfeiçoamento das teorias newtonianas nas primeiras décadas do século XVIII.

Outros autores da época também elaboraram explicações a partir da idéia de forças entre a luz e a matéria, como Richard Helsham em seu A Course of Experimental Philosophy (1739).

Essa curva dos raios, na sua passagem de um meio para outro, parece ser devida a uma força atrativa do meio mais denso agindo sobre os raios em ângulos retos à superfície, como parece ao se considerar as conseqüências de tal atração. [23, p. 289]

John Rowning (1701-1771) também explorou o tema em sua obra A Compendious System of Natural Philosophy, cujos volumes foram publicados em 1734 e 1738. Seguindo a tendência do período, Rowning defendia que a óptica deveria ser um ramo da dinâmica de partículas de Newton. Segundo ele, haveria três classes de forças entre corpos: ação de gravitação agindo a longas distâncias, ação de repulsão agindo a curtas distâncias e ação de coesão também agindo a curtas distâncias. Esta última se manifestaria pela ação de forças atrativas sobre os raios de luz. Assim como muitos seguidores de Newton, ele não conseguiu explicar a reflexão a partir desses pressupostos [18]. Contudo, a classificação de Rowning representa um importante contraste com as teorias da época, visto que ele procurou estabelecer diferenças, e não buscar unificar tais forças.

Essa breve análise de parte dos trabalhos de alguns dos seguidores de Newton do início do século XVIII evidencia a forte tendência em estruturar um modelo dinâmico para explicar os fenômenos ópticos baseado na materialidade da luz. De uma maneira geral, podemos dizer que estes pesquisadores não apresentaram contribuições significativas à pesquisa em óptica do ponto de vista teórico e experimental, mas selecionaram, desenvolveram e divulgaram idéias newtonianas. A maioria das obras desses autores faz referência a Newton, geralmente exaltando seu método de trabalho e suas teorias.

As obras dos seguidores de Newton buscaram unir os conceitos de seus livros mais importantes, o Óptica e os Principia. Contudo, vimos que essa união não logrou construir um sistema completo e coerente. Os argumentos e conceitos apresentados por esses autores têm um forte caráter especulativo, o que contraria o ideal indutivista por trás dessas discussões. A ausência de formulações matemáticas nessas explicações também é um fato problemático, uma vez que elas ficaram com um aspecto extremamente qualitativo, muito diferente da mecânica newtoniana. Certos conceitos criados pelos seguidores de Newton, tais como "espaço de atração" e "espaço de atividade", e os vários tipos de forças discutidas evidenciam algumas das dificuldades envolvidas no estabelecimento de uma "força óptica" única.

Contudo, isso não pareceu um problema para a sociedade científica no início do século XVIII. Este modelo dinâmico para a óptica, juntamente com o corpo da ciência e a filosofia newtonianas foram amplamente propagados não só na Grã-Bretanha, mas também por toda a Europa, principalmente em conferências de cientistas para públicos leigos e livros populares.

\section{A divulgação da óptica newtoniana}

Como vimos, a óptica estudada e adotada por muitos filósofos naturais no início do século XVIII não foi exatamente a óptica proposta por Newton, mas sim um sistema simplificado e fortemente baseado na corpuscularidade da luz. Um dos principais canais de divulgação desta nova óptica newtoniana na Europa foram as conferências públicas sobre temas científicos.

Impulsionadas pelo crescente desejo da sociedade do século XVIII em tornar o conhecimento científico acessível para todas as classes sociais [24], as conferências dirigidas a um público geral conseguiam mostrar abstrações e conceitos científicos de forma simples, principalmente pelo amplo uso de experimentos de fácil manuseio, com resultados visíveis e fáceis de serem entendidos como forma de ilustrar as apresentações e torná-las mais atrativas ao público [25].

Dentre essas conferências, destacamos as de John Teophilous Desaguliers (1683-1744), que ficou muito conhecido na sociedade científica da época por sua defesa da teoria newtoniana sobre luz e cores, principalmente em suas duas maiores obras, o PhysicoMechanical Lectures (1717) e o A Course of Experimental Philosophy (1734), ambas conjuntos de aulas sobre filosofia natural.

Os cursos proferidos por Desaguliers eram freqüentados por vários tipos de pessoas, tais como clérigos, artesãos, nobres, entre outros; e tornaram-se um modelo para as conferências científicas do período [24]. Vários outros filósofos naturais da época, como Helsham e Rowning ofereceram cursos parecidos ao de Desaguliers. As conferências de Desaguliers apresentavam a filosofia natural como um conjunto de verdades sobre a natureza, ilustrando aplicações práticas da filosofia natural, como o uso das lentes para corrigir defeitos da visão. Elas também utilizavam uma abordagem dinâmica para explicar os fenômenos naturais. Seus cursos continham diversas demonstrações de fenômenos de vários tipos, não necessitavam de conhecimento matemático e utilizavam uma linguagem fácil e acessível para os leigos em filosofia natural [18]. 

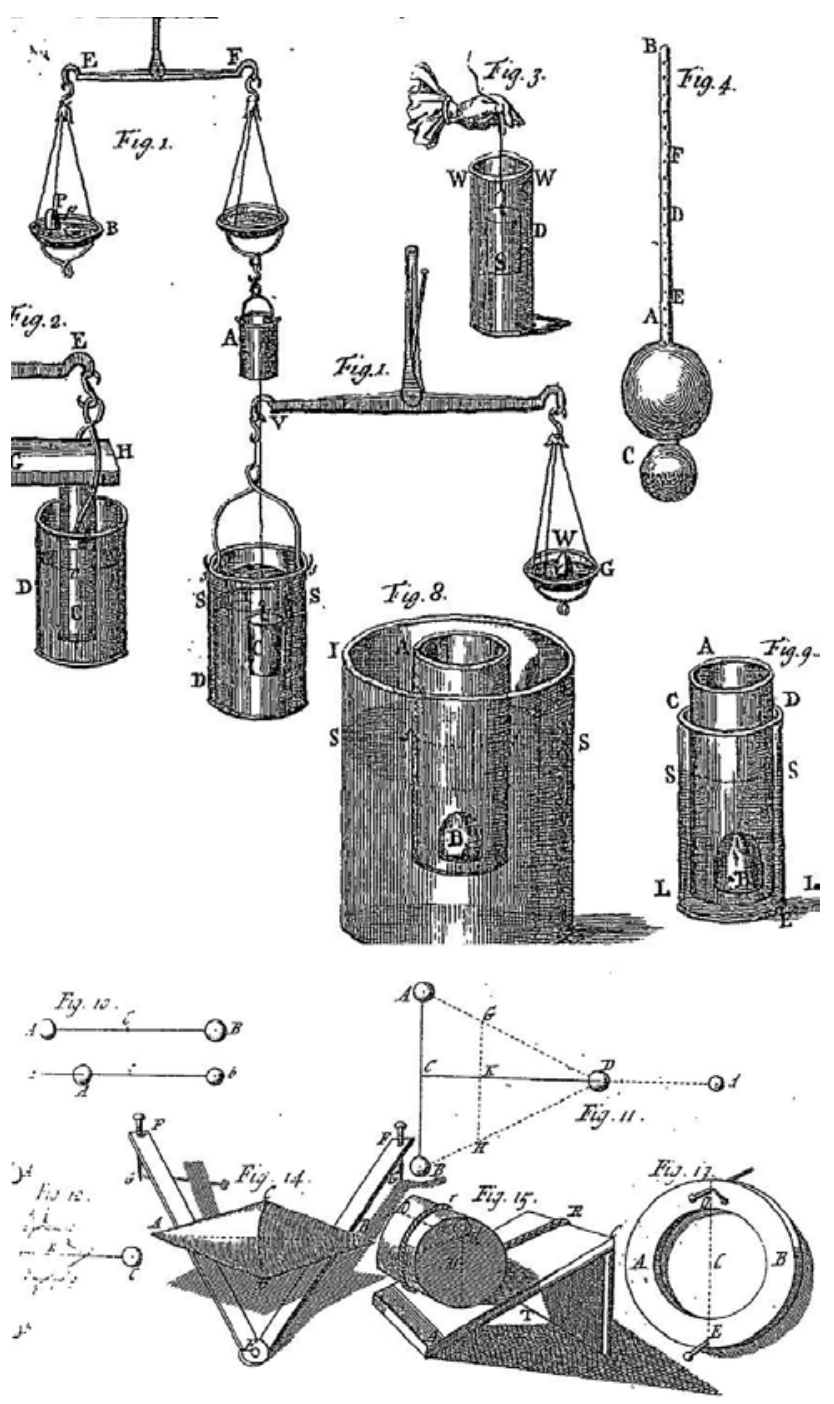

Figura 6 - Desenhos do livro A Course of Experimental Philosophy, de Desaguliers, ilustrando experimentos usados em suas conferências.

No que se refere à óptica, as conferências de Desaguliers - e conseqüentemente de outros filósofos naturais - procuraram apresentar e divulgar o modelo dinâmico para a luz, sem discussões muito detalhadas. Fenômenos cujo tratamento necessitaria de uma análise mais complicada do comportamento da luz, como a dupla refração, os "anéis de Newton" e a inflexão da luz não eram abordados nestas conferências. Para defender pontos como a materialidade da luz, as conferências geralmente se apoiavam nos argumentos presentes no Óptica e nos Principia sobre a analogia entre o comportamento da luz e das partículas de corpos materiais. Essas conferências não discutiram partes da óptica newtoniana que não poderiam ser incorporadas nesse modelo dinâmico para a luz, como a teoria dos estados de fácil transmissão e fácil reflexão. Além disso, afirmavam que outras teorias disponíveis na época para a luz, como as vibracionais elaboradas por Hooke e Huygens, não explicavam satisfatoriamente todos os fenômenos que a teoria corpuscular explicava [18].
Além das conferências, livros populares como o $\mathrm{Il}$ Newtonianismo per le Dame Ovvero Dialoghi Sopra la Luce e i Colori (1737), do italiano Francesco Algarotti ajudaram no estabelecimento da óptica newtoniana na Europa no século XVIII. Neste livro, Algarotti expõe a teoria newtoniana de luz e cores em um diálogo entre um cavaleiro e uma marquesa. Dividido em seis leituras, a obra versa sobre diversos fenômenos ópticos de forma simples e convidativa. O livro foi traduzido para vários idiomas e foi um dos mais lidos na Europa no século XVIII, tornando-se um importante canal para a popularização tanto da óptica, quanto da filosofia newtoniana [26].

Portanto, durante as primeiras décadas do século XVIII, a concepção corpuscular para a luz baseava-se nas Questões e nos experimentos do Livro I de Óptica, sendo tratada como parte da mecânica de Newton e colocada de uma forma didática e sistemática, destacando o caráter empiricista e indutivista da ciência newtoniana, e ignorando seus problemas e aspectos obscuros.

\section{A óptica newtoniana questionada}

A situação só começou a mudar a partir da década de 1750, quando a pesquisa em óptica recomeçou e os problemas com o modelo dinâmico para a óptica e com alguns aspectos das teorias newtonianas se tornaram evidentes [18]. Nesse período, livros e artigos de importantes defensores de outras teorias para a luz, como a vibracional, surgiram. Entre eles, destacam-se o Nova Theoria Lucis et Colorum de Leonhard Euler (17071783), o New Experiments in Electricity de Abraham Bennet (1749-1799), A Dissertation Upon the Philosophy of Light, Heat and Fire de James Hutton (17261797) e An Attempt to Demonstrate, that all the Phaenomena in Nature may be Explained by Two Simple Active Principles, Attraction and Repulsion de Gowin Knight (1713-1772). Os principais problemas por eles apontados estavam relacionados com a determinação da massa e volume das partículas de luz, com a influência da gravitação no movimento dos raios de luz, com as explicações sobre a inflexão e com a idéia de força de curto alcance entre a luz e os corpos, conceito largamente utilizado no início do século XVIII, como vimos acima.

Além disso, havia os fenômenos que não podiam ser explicados pelo modelo dinâmico newtoniano, como os anéis de cores em filmes finos, explicados no Óptica pelo uso do conceito de estados de fácil transmissão e estados de fácil reflexão. Os poucos livros que tratavam do assunto consideravam a teoria pouco clara. No entanto, não havia um consenso geral sobre uma alternativa satisfatória [18].

Além disso, neste período, teorias vibracionais para a luz começavam a ganhar força, principalmente pelo fato de explicarem de forma mais clara e quantitativa fenômenos que a teoria corpuscular não explicava, como 
o fenômeno dos "anéis de Newton", a polarização e a difração da luz (em linguagem atual). Apesar de ainda contar com poucos adeptos, o crescente número de trabalhos baseados nessa concepção, principalmente os de Thomas Young (1773-1829), William Wollaston (17661828) e David Brewster (1781-1868), deram um grande impulso para o posterior desenvolvimento da teoria ondulatória da luz, para o qual os trabalhos de Augustin Fresnel (1788-1827) tiveram um papel decisivo [27].

Sendo assim, ao contrário da sistematização da teoria corpuscular na primeira metade do século XVIII, que ignorou os aspectos conceitualmente problemáticos e obscuros do Óptica, algo muito diferente ocorreu durante o resto do século e no início do século XIX. Algumas idéias da teoria corpuscular começaram a ser questionadas, abalando, assim, sua hegemonia. Apesar da idéia de a luz consistir em partículas não ser muito criticada e mesmo ganhar força pela relação com desenvolvimentos da química, a falta de uma lei universal e satisfatória de força de curto alcance e as dificuldades para explicar os vários fenômenos ópticos de forma unificada fizeram com que a teoria corpuscular nesse período, passasse a ser fortemente questionada [18].

A partir da década de 1830, a teoria corpuscular já não contava com muitos adeptos, sendo, aos poucos, rejeitada pela sociedade científica da época.

\section{O que podemos aprender com esse episódio?}

A análise histórica do processo de aceitação e posterior crítica da óptica newtoniana ao longo do século XVIII mostra que a construção do conhecimento científico e seu reconhecimento pela sociedade é influenciado por muitos fatores, como o prestígio de um cientista para o estabelecimento de sua visão de mundo. Provavelmente, se Newton não fosse tão famoso e exaltado no século XVIII, suas teorias não teriam atraído tantos adeptos, como aconteceu com idéias de outros autores, por exemplo, a concepção ondulatória para a luz de Christiaan Huygens (1629-1695), ignorada pela maioria dos filósofos naturais no século XVIII [28]. Além disso, a grande fama e reconhecimento de Newton como um grande filósofo natural ao longo do século XVIII contribuiu para que muitos aspectos problemáticos de suas idéias não fossem analisados criticamente e, muitas vezes, relevados.

O breve estudo histórico apresentado no presente artigo indica que, muitas vezes, as teorias originais dos cientistas não são propagadas em sua forma original, mas sofrem significativas modificações e são incorporadas nos modelos defendidos no período. Isso é evidenciado pelos esforços dos seguidores de Newton em elaborar um modelo dinâmico para a óptica, ignorando diversas idéias newtonianas que não poderiam ser adaptadas a ele, bem como seus problemas conceituais e de fundamentação teórica e experimental.
As críticas sofridas pela concepção corpuscular após a metade do século XVIII, por sua vez, mostram que a óptica newtoniana não ficou imune a questionamentos, tampouco permaneceu sempre superior em relação a outras teorias para a luz, como a vibracional.

Esses pontos deixam clara a complexidade da natureza da ciência, destacando sua estrita relação com a sociedade, influenciando e sendo influenciada por ela de diversas formas, como, por exemplo, política, social, econômica, cultural e até mesmo por convicções religiosas [29], ao contrário do que muitos professores, mesmo de nível universitário, ainda pensam.

O conhecimento científico é estruturado e consistente, porém, ao mesmo tempo sofreu ao longo da história modificações e alterações importantes para o seu avanço, mostrando que o conhecimento atualmente aceito não é de forma alguma definitivo, sendo as teorias aceitas atualmente passíveis de modificações, da mesma forma que as anteriormente aceitas também o foram. Assim, o estudo da aceitação e desenvolvimento da óptica newtoniana durante o século XVIII evidencia o caráter provisório da ciência, dando bons exemplos de que não existe conhecimento científico neutro, verdadeiro e definitivo.

\section{História e filosofia da ciência e a prática docente}

A necessidade de professores terem uma noção adequada sobre a ciência é fruto de pesquisas realizadas nas últimas décadas [6, 30-32]. Estas pesquisas avaliam a visão de ciência de professores na ativa ou em fase final de formação [33, 34] e também como essas visões influenciam suas atividades em sala de aula de forma explícita ou implícita [35]. Estas pesquisas mostram que os professores muito freqüentemente crêem em um modelo indutivista de pesquisa científica [32, 36]. Muitos professores tentam mostrar como se obtém uma teoria a partir de observação e experimentos ou como se pode provar uma teoria - apesar da impossibilidade filosófica de ambas as tentativas [37]. Parte destes problemas pode ser atribuído a formação inicial e continuada de professores que não aborda questões relacionadas com história da ciência e NDC na profundidade necessária. No entanto, os livros didáticos também têm sua parcela de responsabilidade nesta questão, uma vez que a história da ciência que propagam normalmente é simplificada, distorcida e induz visões equivocadas acerca da NDC [38].

Portanto, se pretendemos formar professores capazes de discutir não só a ciência, mas também sobre ela, e se almejamos um aluno consciente do mundo em que vive e apto a compreendê-lo, é necessário que outras abordagens sejam realizadas tanto na formação de professores quanto em sala de aula. O estudo da natureza da ciência (NDC) pode facilitar essa mudança. 


\section{A natureza da ciência}

Ao longo dos anos, a expressão "natureza da ciência" teve diferentes significados, sendo equivalente a "método científico" no início do século XX até as concepções mais refinadas das últimas décadas. No entanto, entre historiadores, filósofos da ciência, cientistas e educadores nunca houve um acordo completo sobre o que é e quais as características principais da NDC [36].

Alguns pontos importantes sobre a NDC ainda são temas de grande discussão por parte de alguns pesquisadores, como por exemplo, a influência de fatores sociais e históricos na construção do conhecimento científico. A maioria dos pesquisadores considera que esses fatores desempenham um importante papel na ciência, contudo, há um desacordo sobre sua origem e importância. Além disso, há a questão da veracidade ou falsidade das teorias científicas serem determinadas pelas características do mundo, independentemente dos cientistas. Alguns advogam que o mundo é quem determina o valor de uma teoria científica, enquanto outros afirmam que a natureza é determinada pelas avaliações subjetivas dos cientistas [39].

Apesar disso, há alguns pontos que são consenso entre a maioria dos pesquisadores sobre o assunto [40]. Entre eles destacamos:

- O conhecimento científico enquanto durável, tem um caráter provisório;

- O conhecimento científico se baseia fortemente, mas não totalmente, na observação, em evidências experimentais, em argumentos racionais e no ceticismo;

- Não existe um método único de se fazer ciência;

- A ciência é uma, de muitas, tentativas de explicar os fenômenos naturais;

- Muitas pessoas contribuem para o desenvolvimento de teoria científicas;

- Cientistas são criativos;

- A ciência é parte de tradições culturais e sociais.

Os acordos e desacordos sobre o que é natureza da ciência evidenciam a complexidade do assunto. Porém, eles também mostram as inúmeras possibilidades de discussão sobre a ciência, destacando o fato de que nenhum tipo de conhecimento é consensual.

A história e filosofia da ciência é um dos caminhos para introduzir discussões sobre a NDC em sala de aula. O estudo de episódios históricos pode oferecer uma ampla discussão sobre o processo de construção e divulgação de determinadas teorias científicas, suas influências sobre a sociedade da época e a sua eventual rejeição, o que mostra que a natureza da ciência não é simples e tampouco de fácil entendimento, mas rica em detalhes e extremamente fascinante aos olhos de quem a vê.

\section{Referências}

[1] E. Zimmermann, in Atas do VI Encontro de Pesquisadores em Ensino de Física (SBF, Florianópolis, 1998).

[2] K. Dawkins and D. Dickerson, in Proceedings of the $76^{\text {th }}$ Annual Meeting of the National Association for Research in Science Teaching (NARST, Philadelphia, 2003). Disponível em http: //www.ecu.edu/cs-educ/csmte/upload/student $\{-\}$ conceptions $\left\{{ }_{-}\right\}$scientific $\left\{{ }_{-}\right\}$theories.pdf, acessado em 21/8/2007.

[3] S. Liu and N. Lederman, in Proceedings of the $76^{\text {th }}$ Annual Meeting of the National Association for Research in Science Teaching (NARST, Philadelphia, 2003). Disponível em http://eric.ed.gov/ERICDocs/data/ ericdocs 2 sql/content $\left\{{ }_{-}\right\}$storage $\left\{{ }_{-}\right\} 01 / 0000019 b /$ 80/1a/e7/b5.pdf, acessado em 21/8/2007.

[4] D. Gil, Enseñanza de las Ciencias 10, 102 (1992).

[5] F. Bevilacqua and E. Gianetto, Science \& Education 5, 235 (1996).

[6] M. Matthews, Caderno Catarinense de Ensino de Física 12, 164 (1995).

[7] Brasil, Parâmetros Curriculares Nacionais para o Ensino Médio (PCNEM) - Parte III - Ciências da Natureza, Matemática e suas Tecnologias (MEC/SEB, Brasília, 2000).

[8] I. Newton, Óptica (Edusp, São Paulo, 1996).

[9] B. Moura e C. Silva, Atas do X EPEF: EPEF 20 anos (SBF, São Paulo, 2007).

[10] C. Silva, A Teoria das Cores de Newton: Um Estudo Crítico do Livro I de Opticks. Dissertação de Mestrado, Instituto de Física "Gleb Wataghin", 1996.

[11] A.I. Sabra, Theories of Light from Descartes to Newton (Cambridge University Press, Cambridge, 1981).

[12] E. Whittaker, A History of the Theories of Aether and Electricity - The Classical Theories (Thomas Nelson and Sons Ltd., London/New York, 1951).

[13] M. Schenberg, Pensando a Física (Landy Editora, São Paulo, 2001), p. 60-61.

[14] http://plato.if.usp.br/1-2003/fmt0405d/ apostila/oticacorp/node5.html, acessado em $29 / 8 / 2007$.

[15] http://www.seara.ufc.br/folclore/folclore136. htm, acessado em 29/8/2007.

[16] A. Shapiro, Fits, Passions and Paroxysms (Cambridge University Press, Cambridge, 1993).

[17] I. Newton, in Isaac Newton: Textos, Antecedentes e Comentários, editado por I.B. Cohen e R. Westfall (EdUerj/Contraponto, Rio de Janeiro, 2002).

[18] G.N. Cantor, Optics After Newton - Theories of Light in Britain and Ireland 1704-1840 (Manchester University Press, Manchester, 1983).

[19] C. Silva e R. Martins, Ciência e Educação 9, 53 (2003). 
[20] J. Harris, Lexicon Technicum; or, an Aniversal English Dictionary of Arts and Sciences, Explaining not only the Terms of Art, but the Arts Themselves, v. 2 (London, 1723), $2^{\text {a }}$ ed.

[21] W.J. 'sGravesande, Mathematical Elements of Natural Philosophy Confirmed by Experiments, or an Introduction to Sir Isaac Newton's Philosophy, v. 2 (London, 1726), $2^{\mathrm{a}}$ ed.

[22] R. Smith, The elementary parts of Dr. Smith's Compleat System of Opticks, Selected and Arranged for the Use of Students at the Universities: To which are Added in the Form of Notes Some Explanatory Propositions from Other Authors (Cambridge, 1778).

[23] R. Helsham, A Course of Lectures in Natural Philosophy, edited by Bryan Robinson (London, 1767), $4^{\mathrm{a}}$ ed.

[24] N. Hans, New Trends in Education in the 18th Century (Routledge, London, 1998).

[25] G.L.E. Turner, in The Cambridge History of Sciente v. 4 - Eighteenth Century Science, edited by R. Porter (Cambridge University Press, Cambridge, 2003).

[26] M. Mazzotti, British Journal for the History of Science 37, 119 (2004).

[27] J.B. Buchwald, The Rise of the Wave Theory of Light (The University of Chicago Press, Chicago, 1989).

[28] C. Hakfoort, Optics in the Age of Euler - Conceptions of the Nature of Light, 1700-1795 (Cambridge University Press, Cambridge, 1995).
[29] T. Forato, in Estudos de História e Filosofia das Ciências: Subsídios para Aplicação no Ensino, editado por C. Silva (Editora Livraria da Física, São Paulo, 2006).

[30] J.T. Robinson, Journal of Research in Science Teaching 3, 37 (1965)

[31] O.A. Abimbola, School Science and Mathematics 83, 183 (1983)

[32] D. Hodson, Studies in Science Education 12, 25 (1985).

[33] J.M. Aguirre, S.M. Haggerty and C.J. Linder, International Journal of Science Education 12, 381 (1990).

[34] N.G. Lederman, Journal of Research in Science Teaching 29, 331 (1992).

[35] F. Abd-El-Khalick, R. Bell and N.G. Lederman, Science Education 82, 417 (1998).

[36] F. Abd-El-Khalick and N.G. Lederman, International Journal of Science Education 22, 665 (2000).

[37] R. Martins and C. Silva, Science \& Education 10, 287 (2001).

[38] C.R. Pagliarini, Uma Análise da História e Filosofia da Ciência Presente em Livros Didáticos de Física para o Ensino Médio. Dissertação de Mestrado, Instituto de Física de São Carlos, 2007.

[39] J.T. Eflin, S. Glennan and G. Reisch, Journal of Research in Science Teaching 36, 107 (1999).

[40] W.F. McComas, H. Almazroa and M.P. Clough, Science \& Education 6, 511 (1998). 